\title{
Interactive comment on "Investigating
} Wavelength-Dependent Aerosol Optical Properties

\section{Using Water Vapor Slant Column Retrievals from CLARS over the Los Angeles Basin" by \\ Zhao-Cheng Zeng et al.}

Zhao-Cheng Zeng et al.

zzhaoch@gmail.com

Received and published: 28 October 2016

The comment was uploaded in the form of a supplement:

http://www.atmos-chem-phys-discuss.net/acp-2016-490/acp-2016-490-AC2-

supplement.pdf

Interactive comment on Atmos. Chem. Phys. Discuss., doi:10.5194/acp-2016-490, 2016. 